\title{
El don del Espíritu y la justicia escatológica
}

\author{
I. INTRODUCCION: La justicia escatológica idea unificadora \\ de la Biblia.
}

Este artículo quiere ser análogo a otro publicado recientemente sobre un tema perteneciente al mismo ámbito, al ámbito de la "justicia escatológica" 1 .

Es claro que el tema de la "justicia", rectamente entendido el término en el sentido bíblico, unifica, con gran coherencia, sin infligir ninguna violencia al pensamiento, todo el Antiguo y el Nuevo Testamento. No se niega que se puedan detectar "desviacionismos" a veces, pero aun esos que pudieran ser calificados como desviacionismos, no llegan a romper la unidad del pensamiento principal sino que la resaltan por contraste ${ }^{2}$.

Especifiquemos, aunque en plan de resumen, lo que acabamos de formular. Hay que empezar por depurar el significado de los têrminos más empleados para designar la idea de "justicia". Tales son, por ejemplo, los de la raíz "sapat" (que aparece traducido en las versiones corrientes por "justicia" o "juzgar"). Un estudio apurado muestra que tales términos designan ante todo una acción liberadora o salvadora respecto de los oprimidos y necesitados, en equivalencia a lo que en el Nuevo Testamento se expresa más frecuentemente con el término de "amor" al necesitado" 3. En líneas generales, la "justicia del Antiguo Testamento" es el "amor al prójimo ne-

1. "El Mesías y la realización de la justicia escatológica": Mesianismo y Escatología (Estudios en Memoria del Prof. Dr. Luis Arnaldich Perot) (1976) 6184. Igualmente en Salmanticensis 23, fasc. 1 (Enero-Abril 1976).

2. De "desviacionismo" se podria calificar, tal vez, el hecho de que habiéndose alzado los Profetas antexílicos a favor de la "justicia" (el mispat) contra el culto, retorna después, en los profetas postexílicos, en general, un recrudecimiento del culto, sin apenas mención de la "justicia".

3. Ese estudio hemos tratado de hacerlo en "Términos bíblicos de justicia social traducción de equivalencia dinámica": 'Estudios Eclesiásticos 51 (1976) 95128. Se puede advertir que en todo el ámbito bíblico de la justicia social, por defecto de "traducción de equivalencia dinámica", se ha efectuado consciente o in- 
cesitado" del Nuevo Testamento. Sobre esta base se advierte esta linea que corre por todo el Antiguo Testamento y desemboca y continúa en el Nuevo Testamento. Podríamos sintetizarlo en la frase que "el Dios de la Biblia es el Dios interpelante a la justicia interhumana”. Esta parece ser la caracterización más prominente en el Dios que se revela en la Biblia. Baste con apuntar algunos rasgos.

1. Su intervención en Egipto es para la liberación del pueblo oprimido. Lucha contra la injusticia y a favor de la justicia ".

2. El Yahvista concibe el Génesis como prólogo al Exodo y tiene, entre otras cosas, el pintar a Yahvé que escoge a Abraham, es decir al pueblo de Israel (al pueblo de la Biblia), para practicar y enseñar a practicar "el derecho y la justicia" (Gén 18,18), términos técnicos para indicar la justicia interhumana especialmente con los débiles. Este punto es de suprema importancia. En él se da la razón de la elección de Israel. Israel es elegido como instrumento de Yahvé para la realización de su plan de establecer la justicia perfecta en el mundo. Ese pasaje del Génesis es en compendio toda una Teologia sobre la intervención de Yahvé en la historia humana y la misión de Israel en medio de ella.

3. El pueblo de Israel le falló a Yahvé en la misión que le confiara y para la que le había escogido. Esto es lo que se dice en Is 5,1 y ss, en la alegoría de la viña. La interpretación de la alegoría es que esperaba del pueblo escogido "justicia" y lo que recogió fue "injusticia interhumana" 5 . En vez de uvas, agrazones. Por eso sería arrasada la viña de elección y desechado el pueblo de Israel.

4. El Mesias, fundamento del futuro pueblo escogido, está designado en muchos pasajes como el implantador de la "justicia escatológica", la justicia perfecta y definitiva. Véase tan sólo la pintura del Siervo cuya misión aparece ser en el Primer Poema la de llevar el "mispat" (El derecho especialmente de los débiles contra los opresores) a las naciones (Is 42,1 ss.).

conscientemente una especie de bloqueo que impide que nos llegue el característico mensaje bíblico. Para poner sóló un ejemplo: Si "mispat" significa preponderantemente el derecho de los desvalidos que Dios cuida de manera singular y quiere establecerlo con perfección en la tierra, en otras maneras mediante la actuación de su instrumento el Siervo de Yahvé, quién entiende Is 42,4 si está traducido, refiriéndose al Siervo que "no desmayará hasta implantar en la tierra el "juicio" ("¿mispat?").

4. Aquí resumimos del artículo de la nota 1 .

5. En el hebreo existe un juego de palabras: En vez de "mispat" - justicia, "mispast" - asesinato ; en vez de "sedapah" - justicia, "sea'qah" - el clamor (ante la injusticia). 
5. Si nos fijamos en la teologización de la Ley, ésta apàrece, hechas las discusiones pertinentes, con el único contenido de justicia interhumana. Todo el Decálogo, quintaesencia de la Ley, está centrado en el amor del prójimo, aun esos primeros preceptos que parecen más claramente referirse a Dios, o tener a Dios como objeto y no al prójimo.

Si el Decálogo empieza "Yo soy Yahvé, tu Dios que te sacó de Egipto", es para caracterizar esencialmente a ese Dios, Yahvé, que se reveló como el único Dios haciendo justicia para con el prójimo - liberando al oprimido. Si se prohibe tener a otro Dios, es porque otros dioses (fuera de Yahvé) no son interpelación a la justicia.

Y la "prohibición de representar a Yahvé en imágenes" está demostrado que es para no evadir lo que Yahvé es, es decir, interpelación a la justicia interhumana. Representarlo en imágenes : sería objetivarlo, convertirlo en cosa de contemplación o de culto. $Y$ la interpelación no puede ser objetivada sino escuchada y obedecida. No puede ser objeto del entendimiento, sino orden que se cumple. $Y$ la orden es la justicia interhumana ${ }^{6}$.

6. Toda la orientación del Antiguo Testamento va en la dirécción de una justicia escatológica que se realizará un día perfectamente. En la literatura apocalíptica ese anhelo se hace especialmente angustioso. Cuándo y cómo se realizará, o si ello es una utopia; o si esa justicia ideal es algo que se forjaron unas mentes soñadoras obsesionadas de reivindicaciones es otro problema?. Lo que es cierto es que la idea y el hambre de justicia invade toda la Biblia; y que el Dios de la Biblia aparece caracterizado como el Dios de la justioia interhumana.

Dentro de este encuadramiento creemos que debe estar colocada la teología del Espíritu Santo. El Espíritu, por lo menos como don escatológico, está en íntima relacción con el don de la justicia, como lo muestran multitud de pasajes del Antiguo y del Nuevo Testamento. Prescindimos de las acepciones que primeramente pudo tener la palabra "espíritu", y nos concentramos en la acepción que por lo menos tardiamente tomó el término".

6. Lo hemos tratado en "El alcance de la "prohibición de las imágenes" en el Decálogo Mosaico": Estudios Eclesiásticos 48 (1973) 315-326. nota: 1

7. Para este punto del cumplimiento; de nuevo citamos el artículo de la ... 8. Damos a continuación una breve bibliografía selecta sobre teología biblica: del Espíritu: P. VAN IMSCHOOT, "Teología del Antiguo Testamento" (trad. española): Actualidad Bíblica 12 (1969); el original francés es de 1966, 
II. Consideración de algunos pasajes como punto de partida

1. En el capítulo 3 de la epístola a los Gálatas existe una interpretación de la promesa hecha a Abraham. Esa interpretación es la formulación de la tesis que propugnamos.

1. La promesa hecha a Abraham aparece en los capítulos del Génesis como un conjunto de cosas. Abraham es escogido por Dios para realizar su plan de establecer en el mundo la justicia perfecta. Los primeros capitulos del Génesis exponen cómo el Pecado entró en el mundo, Pecado de Injusticia, y lo invade y lo perturba todo. Por el Pecado del hombre la "maldición" actúa en todo con virulencia.

El plan de Dios es escoger un hombre cuya descendencia multiplicará y por quien vendrá la "bendición" a todos los pueblos de la tierra. Pero esta "bendición" ha de venir porque Abraham y su descendencia han de practicar la justicia y han de enseñar a practicarla.

Esto se afirma claramente en Gén 18, 18-19: "Abraham (son palabras de Yahvé) ha de convertirse en una nación grande y poderosa, y en él van a ser bendecidas todas las naciones de la tierra; (¿cómo?) pues me he fijado en él, para que él mande a sus hijos y a su casa después de él que guarden el camino de Yahvé /de justicia/ (¿cómo?) practicando la justicia y el derecho/mispat wesedaqah/, a fin de que Yahvé haga venir sobre Abraham lo oue le tiene prometido" (es decir, la bendición de todas las naciones de la tierra).

La promesa abarca, pues, la descendencia y la "bendición universal" mediante la práctica de la justicia. La descendencia no viene directamente en la promesa, sino en cuanto orientada a la bendición universal por la justicia.

2.: En Gál 3,8b habla Pablo, citando al Génesis, de la "bendición" prometida a Abraham. Pero un poco más adelante (Gál 3,14)

Tournai, Bélgica. En el capítulo sobre "el Espíritu" tiene una suficientemente amplia bibliografía. Resaltamos un artículo procedente del mismo VAN IMSCHOOT, "L'esprit de Yahvé, principe de vie morale dans l'A. T.": Ephemerides Theologicae Lovanienses" (1939) 457-567. Más especialmente para el Nuevo Testamento se puede citar: E. BARDY, Le Saint-Esprit en nous et dans l'Église d'apres le Nouveau Testament. Albi, 1950 ; S. ZEDDA, L'adozione e figli di Dio e lo Spirito Santo. Roma, 1952; H. MOHLEN, El Espíritu Santo en la Iglesia (traducción española). Salamanca, 1974. El presente artículo ha querido ser la ampliación de unas páginas muy sugerentes del libro de J. P. MIRANDA. Marx y la Biblia (Salamanca 1972) 247-255, donde trata precisamente de la "relación entre espíritu y justicia". 
nos encontramos con estas palabras: "Para que sobre las naciones viniera la bendición de Abraham en Jesucristo, para que por medio de la fe recibiéramos la promesa del Espíritu". La bendición prometida a Abraham es interpretada como Espiritu. La promesa se cumple dando Dios su Espíritu. Esto quiere decir, en la línea de lo expuesto en la Introducción, que el espíritu de Yahvé es ante todo "espiritu de justicia interhumana". Y de aquí se desprende que "espiritu" hay que tomarlo ante todo como una "caracterización", como cuando se dice o se puede decir del miembro de un instituto religioso que tiene el espiritu de su fundador cuando realmente procede y actúa como e1. No se excluye el aspecto personal, pero no es eso lo que se afirma directamente. Sobre el texto de Gálatas más en concreto, volveremos a su tiempo. De momento baste haber notado la equivalencia entre "espíritu" y "justicia interhumana", equivalencia que Pablo da como sobreentendida?.

2. Se pueden considerar otros textos del tiempo de la Promesa de íntima relación entre "Espíritu" y Justicia".

1. En el capitulo 28 de Isaias, se dice refiriéndose al futuro escatológico, (v. 17): "Pondré el derecho como medida y la justicia como nivel". Poco antes, esta orientación según la justicia en el futuro escatológico, en otra formulación, estaba puesta en relación con el "espíritu de Yahvé". En Is 28, 5-6 se dice que "Yahvé será espiritu de justicia" para los que presiden el "mispat" (los que están comisionados parà defender los derechos de los débiles) ${ }^{10}$. El trasfondo de esta frase es la escena descrita en Números 11, 16-29, en la que a los 70 colaboradores de Moisés en el gobierno del pueblo se les da "el espíritu de Yahvé", igual que a Moisés, para desempeñar la misión de justicia (vv. 17 y 29).

El espíritu de Yahvé para los que presiden el mispat, es espiritu de justicia. La caracterización esencial de Yahvé, lo que le distingue de otros dioses, es el sentido ilimitado de justicia, como aparece en el Exodo y en toda la historia, según hemos apuntado en la Introducción. Su espiritu es ése. Se entiende cualitativamente. El espiritu de justicia pasa a Moisés y a los colaboradores de Moisés y será un atributo del futuro escatológico, según Isaías 28: "espíritu de justicia".

2. En Miq 3, 8-10 también se entiende "espíritu de Yahvé" co-

9. Cf. J. P. MIRANDA, Marx y la Biblia, 247, nota 8.

10. Para el sentido exacto de estos términos de "justicia", como "mispat", nos remitimos al artículo citado en la nota 3. 
mo caracterización por la justicia, como manera distintiva de ser y de actuar: "Yo, en cambio, estoy lleno de fuerza del espiritu de Yahvé, de justicia (mispat) y fortaleza, para denunciarle a Jacob su transgresión y a Israel su pecado". (Sigue una denuncia de injusticias).

III. El espiritu de Yahvé en la configuración de la historia de Israel.

De acuerdo con que el pueblo de Israel es un instrumento del plan de Yahvé para la implantación de la justicia, no es de extrañar ver al "espíritu de Yahvé" actuando en la configuración de la historia empirica, y observarle como don prometido para la realización escatológica de la justicia.

\section{A. En la historia empirica de Israel.}

1. En este sentido es interesante notar la intervención del "espíritu de Yahvé" en el "libro de los libertadores" (Libro de los Jueces.) y en el primer Libro de Samuel.

Yahvé se ha revelado por primera vez, en el Exodo, "liberando" de la opresión de Egipto al pueblo de Israel, cuando el pueblo, ya establecido en Canaán, sufre eventuales opresiones. Dios, mediante su "ruaj", suscita en el pueblo jefes carismáticos liberadores. Es el mismo Dios de la liberación de Egipto. El Espiritu de Yahvé viene sobre Otnièl (Jc 3,10), Gedeón (6,34), Jefté $(11,29)$, Saúl (1 Sam 11, 6), David (1 Sam 16,13), etc.

La relación entre "espiritu de Yahvé" y "justicia" es manifiesta. El espíritu de Yahvé va contra la injusticia y a favor de la justicia.

2. Igualmente, de acuerdo con la finalidad de la elección según Gén 18, 18-19, el pueblo de Israel se mantiene como tal, en su especificidad, mediante el espiritu de Yahvé. Esto es lo que está indicado en $\mathrm{Ag} \mathrm{2,5}$, donde están expresamente vinculados la constitución del pueblo de Israel en nación y el espiritu de Yahvé: "Conforme a la alianza que pacté con vosotros a la salida de Egipto, y en medio de vosotros se mantiene mi espiritu. ¡No temáis!”.

3. En otros textos aparece también el Espíritu de Yahvé sobre los Profetas y los Sabios en orden a la justicia o como configuradores de la historia.

11. Para esta traducción de "sopetim", cf. el artículo citado en la nota 3 . 
1..$^{\circ}$ La acción del Espíritu sobre los Profetas para conservar la alianza, es decir para conservar al pueblo en su especificidad (de instrumento para la justicia), aparece claramente en Is 59,21: "Cuanto a mí, ésta es la alianza con ellos, dice Yahvé. Mi espiritu que ha venido sobre ti, y mis palabras que he puesto en tus labios (paralelismo de espíritu y palabra) no caerán de tu boca, ni de la boca de tu descendencia, ni de la boca de la descendencia de tu descendencia, dice Yahvé; desde ahora y para siempre".

2. ${ }^{\circ}$ El Espiritu aparece sobre el Profeta encargado de llevar la buena nueva a los afligidos y oprimidos (Is 61,1 ss.), como antes en el texto de Miqueas. Jesús se äplicará más tarde el pasaje isaiano.

"El Espiritu de Yahvé está sobre mí, pues Yahvé me ha ungido. Me ha enviado para predicar la buena nueva a los abatidos y sanar a los de quebrantado corazón, para anunciar la libertad de los cautivos y la liberación a los encarcelados, 2/ para publicar el año de gracia de Yahvé y un día de venganza de nuestro Dios, para consolar a todos los tristes, 3/ y dar a los afligidos de Sión, en vez de ceniza, una corona, el óleo del gozo en vez del luto, alabanza en vez de espíritu abatido. Se les llamará terebintos de justicia, plantación de Yahvé (para su gloria)".

3. La acción del espiritu sobre este profeta en orden a la justicia es extensible a todos los profetas. El Espiritu aparece como el órgano permanente que, por los profetas, transmite las órdenes de Yahvé a su pueblo (Zac 7,12 ss.) = La predicación de los profetas habia sido para la justicia (en Miqueas es atribuida al Espiritu): "juzgad conforme a verdad, practicad la piedad y la misericordia hacia vuestro prójimo; $10 /$ no oprimáis a la viuda, al huérfano, al extranjero y al hombre, no maquinéis el mal en vuestros corazones el uno contra el otro (Respondieron con un corazón duro). "Pero no quisieron atender $\mathrm{y}$ se hicieron hombres rebeldes $\mathrm{y}$ endurecieron sus oidos para oír. 12/ Se hicieron un corazón duro como el diamante, para no escuchar las enseñanzas y palabras que Yahvé de los ejércitos les mandaba por medio de los profetas primeros" (Ese corazón de piedra Dios lo sustituiria, según Ezequiel (36, 25-28).

4. ${ }^{\circ}$ En Neh 9,30, en la oración de los Levitas, la predicación de los Profetas (orientada hacia la justicia) es atribuida al Espiritu. "Los soportaste largos años amaestrándolos con tu espiritu : y no le dieron oídos" (cfr. 9,20: "Tú les diste tu buen espiritu para enseñarles").

4. También los Sabios, que sustituyen a los Profetas, son detentores del Espiritu para la justicia. 
1. Dice Elihú (Job 32, 7-8): "Me decía... los muchos años darán a conocer la sabiduría. Pero ésta es en el hombre una inspiración y es el soplo del Omnipotente el que enseña" (La Sabiduría, en el supremo estadio, se identifica con la justicia).

En 32,18 repite: "Me insta el Espíritu que hay dentro de mi" (a hablar en defensa de la justicia).

2. Eccl 39,8 /al que quiera ser sabio/ "Si le place al Señor soberano, lo llenará del espiritu de inteligencia".

3. "Invoqué al Señor y vino sobre mí el espíritu de sabiduría" (Sab 7,7). El espíritu de sabiduría en relación con la justicia está descrito en la oración de Salomón (cap. 9) que termina así: “¿Quién conoció tu consejo si tú no le diste la sabiduría y enviáste de lo alto tu espíritu Santo? Así es como se han enderezado los caminos de los que moran sobre la tierra y los hombres supieron lo que te es grato, y por la sabiduria fueron salvos (no sabiduria intelectual, sino práctica de justicia).

5. El Espíritu de Yahvé aparece otras veces fuente de vida justa en el individuo, es decir, en aquellos que han de hacer la historia.

1..$^{-}$Es típico en este sentido el pasaje del Salmo 51 (vv. 12-14): "Crea en mí un corazón puro, oh Dios, y renueva dentro de mí un espíritu firme". Se trata de una trasformación de la misma envergadura que la creación primera. Se emplea el mismo verbo bara. Hacer del egoísta un justo. Es atribuido al Espíritu Santo. "No me arrojes de tu presencia, y no retires tu santo espíritu; devuélveme la alegria de tu socorro y sosténme por un espíritu de buena voluntad".

$28^{\circ}$ El Salmo 143,10 contiene una idea parecida: "Enséñame a hacer tu beneplácito, pues tú eres mi Dios; que tu buen espíritu me guie por el camino llano".

6. El libro de la Sabiduría habla (cf. Is 63,14 ; Neh 9,20) del "Espíritu Santo Educador" (“agion pneuma paideias”).

7. En el libro de la Sabiduria (1,5) "el Espíritu Santo Educador" es un poder divino que forma a los hombres en sabiduria, es decir, en la piedad ( ¿hesed) ${ }^{12}$, que "penetra" $(7,3)$, "vigila" $(7,23)$ todo, y "entiende toda voz". $(1,7)$.

Como la Sabiduría con la que está identificado (1,4 ss.; 9,$17 ; 7$,

12. Cf. el artículo citado en la p. 108, nota 3. 
22-30), dirige, asiste y fortifica al Sabio en el cumplimiento de la voluntad divina; no es pues solamente un mentor que le enseña, sino un principio divino que produce, o más bien sostiene la piedad (¿hesed?). Pues "no entra en el alma que medita el mal (cf. 1.4; 7,25), y no es dado sino a los justos (cf. Sal. 51,13).

\section{B. En la Escatologia}

Aparece el conferimiento del Espíritu, en orden a la justicia, al Mesias y al pueblo escatológico.

1. Para el Mesias, dos son los textos más significativos ${ }^{13}$.

1.' Según Is $11,1-9$, sobre el descendiente de David se posará el Espíritu de Yahvé (v. 2) y (en consecuencia) el descendiente de David "defenderá a los pobres con justicia y con rectitud a los indigentes; herirá al violento con la vara de su boca y matará al injusto con el aliento de sus labios; la justicia será cinturón de sus 10mos y la bondad ceñidor de sus caderas (vv. 4-5). En el reino del Mesias será suprimida la violencia y la injusticia (vv. 6-9).

2. Igualmente sobre la persona del siervo, instrumento de Dios para el futuro, vendrá el espiritu de Yahvé, y como consecuencia llevará el "mispat" (la justicia perfecta) a las naciones (Is 42, 1-4). El Espíritu de Yahvé aparece de nuevo como caracterización de Yahvé, que es el Dios de la justicia interhumana,

2. Para un conferimiento del Espíritu al pueblo escatológico, que se verá realizado en Pentecostés, existen muchos pasajes, todos ellos en relación con la justicia. Veamos algunos.

1. En Is 32, 15-1 se habla de una infusión del "Espíritu de lo alto" que no es otra cosa que lo que se predice en otros textos. Este pasaje contiene esta descripción que es como una descripción de una vuelta al Paraíso:

"Cuando se derrame sobre nosotros el espiritu de lo alto, el desierto será un vergel y el vergel parecerá un bosque: en el desierto morará la justicia (mispat) y en el vergel habitará el derecho (sedaqah); la obra de la justicia será la paz, efecto de la justicia la seguridad y confianza para siempre".

(Lo que aquí está en metáfora se describirá en términos propios

13. Respecto al Espíritu y al Mesías, cf, R. KOCH, Geist und Messias. Beitrag zur biblischen Theologie des Alten Testaments. Wien, 1950. 
en Pentecostés. Véase también Is 44, 3-7 (transformación por el Espiritu); "Derramaré mi espiritu sobre tu linaje (Jacob), mi bendición sobre cuanto de ti nazca. Crecerán como en medio de hierbas, como álamos junto a las corrientes de las aguas").

2. La afirmación de Ezequiel es también bien explicita. Aparece en dos sitios: "Y os aspergearé con aguas puras y os purificaré de todas vuestras impurezas, de todas vuestras idolatrias. Os daré un corazón nuevo, y pondré en vosotros un espiritu nuevo, os arrancaré ese corazón de piedra y os pondré un corazón de carne. /27/ Pondré dentro de vosotros mi espíritu y os haré ir por mis mandamientos y observar mis preceptos y ponerlos por obra. /28/ Entonces habitaréis la tierra que yo di a vuestros padres, y seréis mi pueblo y yo seré vuestro Dios" $(36,25-28)$. La misma idea en Ez 11, 17 20: "Yo les daré un solo corazón ${ }^{14}$ y pondré en ellos un espiritu nuevo: quitarè de su cuerpo el corazón de piedra y les daré un corazón de carne, para que caminen según mis preceptos, observen mis normás y las pongan en práctica, y asi sean mi pueblo y yo sea su Dios".

En Is 5,1 ss. el pueblo era rechazado por no practicar la justicia; aquí el pueblo vuelve a ser tomado, pero es transformado, mediante el espiritu para practicar la justicia. La ley de Yahvé es la justicia interhumana. $Y$ Ezequiel también lo entiende asi, como puede verse en el cap. 18,5 ss.

3. El texto de Joel 3,1 ss., citado en el discurso de Pedro en Pentecostès, habla de una efusión escatológica del espíritu de Yahvé en la era mesiánica venidera, aunque no se encuentra alusión explicita a la justicia, si a la prosperidad y paz paradisiacas que son fruto de la justicia según Is 32 .

\section{El Espiritu en la literatura intertestamental}

1. Aparece en esta literatura una tradición mesiánica que se vincula especialmente a dos pasajes antiguos referentes al Mesías, uno de ellos en íntima relación visible con el Espíritu Santo y la justicia. Los dos pasajes son Is 11 y el Salmo 2. A ellos se pueden añadir los pasajes del Siervo de Yahvé que ya en su origen estaban en alguna manera inspirados en el Salmo 2 y en Is $11^{15}$.

14. Existe aqui cierta fluctuación textual en las versiones: hebreo "un solo corazón" o tal vez, "otro corazón" (griego) o, "un corazón nuevo" (sirio).

15. Para toda esta cuestión (en el bajo-judaísmo y en el Nuevo Testamento) véase la monografía de MAX-ALAIN CHEVALLIER, L'Esprit et le Messie dans le bas-judaisme et le Nouveau Testament. París; 1958. 
1. De Isaías 11 ya hemos visto cómo el futuro Mesias aparece equipado con la plenitud del Espiritu, y que ese equipamiento es para hacer triunfar la justicia respecto de los necesitados y eliminar a los injustos (a los "resáim") ${ }^{16}$. El resultado de la acción del Mesías equipado con el espiritu es la desaparición de sobre la haz de la tierra de toda violencia implantándose asi una convivencia pacífica como en el paraíso.

2. ${ }^{\circ}$ En el Salmo 2 tenemos ante todo que Yahvé consagra a su Mesías que es proclamado como "su hijo". En la conspiración de pueblos y naciones contra Yahvé, el proclamado Mesias será instrumento de Yahvé para sometimiento de las naciones rebeldes.

La relación de este salmo con la "justicia" no es difícil hallarla a través del tema de "Yahvé guerrero", que es tema de justicia (o identificable con "Yahvé justiciero", o que hace justicia).

Ei salmo 2 (lo mismo que el salmo 1) es como un resumen introductorio al salterio. $Y$ una de las ideas centrales del salterio es que Yahvé aparece realizando su plan de establecer la justicia interhumana, al que se oponen, como miembros de un ejército, los "resáim" que por su inmisericordia y sus injusticias impiden que se realice la justicia en el mundo que es el plan de Yahvé (cf. Sal 3,7; $27,3 ; 55,19 ; 56,2 ; 59,5 ; 62,4)$. Militan contra Yahvé. El resultado de esta lucha está expresado en el Sal 37, 28-29: "Los injustos serán exterminados; la extirpe de los inicuos se extinguirá; los justos poseerán la tierra, la habitarán por siempre jamás".

El tema de "Yahvé guerrero", que corre por la Biblia ya muy desde el principio (cf. Jc 5), lo mismo que el de "Yahvé juez", un estudio detallado manifiesta claramente a qué clase de guerra hace referencia. Se especifica esto, por ejemplo, en el Salmo 147,6 (salmo guerrero); "Yahvé socorre a los menesterosos, y abaja hasta el polvo a los injustos: ("resáim")". Se trata en muchos textos de la justiciera solidaridad de Yahvé con los pobres en contra de los opresores ${ }^{17}$.

Típico salmo de guerra es el salmo 18 que describe a Yahvé en guerra incluso montando en cabalgadura. Pero en el v. 28 nos dice, de nuevo, de qué guerra se trata: "Tú eres el que salva al pueblo pobre y humillas la mirada de los altaneros". Las citas se podrian multiplicar en este sentido.

16. Cf. el artículo citado en la p. 121, nota 3.

17. Sobre el tema de "el Dios guerrero", comparado con el tema "Dios juez": J. P. MIRANDA, Marx y la Biblia, 145-47. 
Volviendo al Salmo 2, el "proclamado hijo" es el debelador de las naciones que militan contra el plan de Yahvé, es el instrumento para implantar la justicia en la tierra.

3. ${ }^{\circ}$ Existen afinidades entre Is 11 y el Salmo 2. La asociación de estos pasajes es anterior a la literatura intertestamental. Aparece claramente en la obra de Isaías, tanto en el ciclo de Enmanuel cuya idea dominante es el triunfo universal de un davídida bendecido de Yahvé, como en el ciclo del Siervo de Yahvé donde aparecen utilizados los temas Is 11,2 y Sal 2. Por ejemplo, 49, 1-9 (el Segundo Poema) contiene claras resonancias del Salmo 2, especialmente en el tema esencial del "hijo".

Es notable la constancia de rasgos que son atribuidos al ungido de Yahvé tal como aparecen en los Salmos y que los resume asi $\mathrm{H}$. Ringgren ${ }^{18}$ : "El rey israelita es el ungido de Yahvé; es instituido por él y es proclamado su hijo. Establecerá en el país el derecho y la justicia, procura a su pueblo la bendición divina, la lluvia y la fertilidad, abate todos los enemigos con su fuerza divina, reina sobre el mundo entero y su trono subsistirá para siempre". (Estos mismos rasgos se encuentran en Isaías).

2. Los dos temas prevalentes, el del Espiritu en Is 11 y el de la "filiación divina" de Sal 2, serán temas básicos en la tradición mesiánica de la literatura intertestamental. Citemos algunos textos:

1. ${ }^{\circ}$ En el Salmo de Salomón 17,42, refiriéndose al Mesías, hay una clara alusión a Is 11,2: "Dios le ha hecho poderoso por el Espiritu Santo y sabio por el don de consejo iluminado, acompañado de la fuerza y de la justicia".

En 17,26b hay una alusión a Sal 2,9: “...de modo que quebrantará el orgullo de los pecadores como vasos de alfarero, de modo que romperá con una vara de hierro toda su substancia". En 17,27 hay una alusión a Is 14,4: “...herirá al hombre violento con la vara de su palabra y con el soplo de sus labios hará morir al "obrador de injusticia".

2. En las Parábolas de Henoc existen también las alusiones al Sal 2 y a Is 11 .

En 48, 2-9 hay una alusión a Sal 2,2. Dice el Salmo: "los príncipes forman una liga contra Yahvé y contra su ungido". Dice He-

18. “König und Messias": Zeitschrift für die Alttestamentliche Wissenschaft (1952) $120-147$. 
noc: "Porque ellos han negado al Señor de los espiritus y a su: ungido".

En 49,3 hay una alusión a Is 11,2: "En él (el elegido) habita el espíritu de sabiduria y el espiritu que ilumina y el espiritu de ciencia $y$ de fuerza".

3. En los Libros Sibilinos (III, 787-794) nos encontramos tambièn alusiones a Is 11, 6-9: "Los lobos y los corderos comerán hierba unos con otros en los montes, etc".

$Y$ a Sal 2, 1-5: "Y los reyes comenzarán a irritarse los unos contra los otros, meditando el mal en su corazón... Y Dios, con su gran voz, hablará a todo este pueblo de vanos pensamientos... todos perecerán bajo la mano del Inmortal".

3. En otros pasajes de la literatura intertestamental hay alusiones al espiritu en cuanto don escatológico o en cuanto a su actividad moral en los individuos.

1. ${ }^{\circ}$ Se dice en Testamento de Judá $24,2 \mathrm{~b}$ y $3 \mathrm{a}$ : "El derramará sobre vosotros el espiritu de gracia y seréis sus hijos en la verdad" (segủn la versión armeniana: una adopción de verdad).

2. En el Testamento de Sim 4,4 se hace referencia a la actividad del Espiritu en José: "Pero José era hombre bueno, y teniendo el Espíritu de Dios en sí mismo, compadecido y misericordioso, no me guardó rencor, sino que me amó como a los otros hermanos".

3. También en la literatura de Qumran hay alusión a esta actividad del Espíritu:

"El alma de tu servidor ha detestado toda obra de injusticia:

He conocido que el hombre no es justo fuera de ti,

He aplacado tu faz por el espiritu que has puesto (en mi)"

(1 QH 16, 10-11).

V. Consideración del tiempo del cumplimiento (en Jesús y en los cristianos).

Por todo el Antiguo Testamento, sobre todo la última época, corre la idea de una intervención escatológica de Dios para la implantación de la justicia perfecta. Esa intervención de Dios está muchas veces relacionada con el Espíritu Santo como un don escatológico. Esa intervención de Dios anunciada y prometida tiene su cumplimiento en el Nuevo Testamento en Cristo y los cristianos. 
A. El Espiritu Santo actuando sobre Jesús en orden a la justicia.

\section{Cuestion de base}

En cuanto a Jesús y el Espiritu hay un problema de base. El problema es la "ausencia" relativa del Espiritu en el ministerio de Jesús ${ }^{19}$.

Los textos referentes al Espiritu en los Evangelios ofrecen diferencias. Mientras Lucas multiplica los pasajes del Espiritu tanto en el Evangelio como en los Actos, Mateo y Marcos sólo mencionan en siete pasajes al Espiritu Santo en general, y de sólo uno, según los criticos, se podria afirmar con certeza que pertenece a Jesús.

Entonces se puede preguntar por la conciencia que tuviera Jesús de estar movido por el Espiritu a imagen de los antiguos profetas, y por la razón de no haber estado más explícito en este seṇtido.

¿Por qué Jesús; si resaltó su relación con el Espiritu, no resaltó la efusión escatológica que debía caracterizar de manera tan espectacular los comienzos de la Iglesia?

El problema parece que ya preocupó al evangelio de Juan que da una solución no del todo convincente. El Espíritu o el Paráclito habia de ser el "sustituto" del desaparecido Jesús. Si así era, era normal que el Espiritu no hiciese su aparición sino después de la glorificación de Jesús (cf. Jn 7,$39 ; 16,7$ ).

No se ve por que Jesús tiene que irse para que venga el Espíritu. La existencia y la influencia del Espiritu era ya bien conocida del Antiguo Testamento.

Por otra parte, si Jesús no habla apenas del Espiritu Santo, ni por lo que se refiere a los otros, los Sinópticos (y otros autores neotestamentarios) presentan a Jesús particularmente dotado del Espiritu Santo, especialmente a partir de su bautismo, aunque después parece que se eclipsó el papel del Espiritu en el ministerio público de Jesús.

¿La explicación estaría en que el surgimiento de la Iglesia después de la experiencia de la resurrección fue una explosión carismática?

Prescindiendo de la cuestión de la relación de los textos con

19. Sobre este punto véase especialmente C. K. BARRET, The Holy Spirit and the Gospel Tradition. London, 1947. Sobre toda la problemática en general, puede verse el artículo de L. LADARIA, "Humanidad de Cristo y don del Espíritu": Estudios Eclesiásticos 51 (1976) 321-345. Es de notar una extrañeza que suscita el cap. 18 de los Apóstoles sobre Apolo, quien estando muy al tanto del "camino del Señor", ignora el bautismo del Espíritu" por Jesús. 
Jesús, está claro que la Iglesia primitiva estableció una estrecha relación del Espíritu Santo con Jesús. Esta relación está establecida por los Sinópticos en la presencia del Espíritu en dos momentos claves y como programáticos, en el bautismo de Jesús y en la anunciación del nacimiento virginal. Existen también diversos pasajes neotestamentarios que presentan la relación de Jesús con el Espíritu en el ministerio público, en la muerte y la resurrección.

2. Jesús en relación con el Espiritu en la escena del Bautismo.

El "Eautismo" está precedido por la predicación de Juan Bautista, en la que aparece la frase: "Yo os bautizo con agua; él os bautizará con el Espiritu Santo y con fuego", y está seguida de la conducción de Jesús al desierto por el Espíritu para ser tentado. Es en el Bautismo donde aparece la primera manifestación de Jesús como Mesías, y esta manifestación aparece expresada según los textos fundamentales de Is 11, y del Salmo 2.

El cuadro está ofrecido por el Salmo 2, 4-7 (proclamación del Mesías por el Señor: "El que se sienta sobre los cielos proclama: Tú eres mi hijo, yo te he engendrado hoy"). A este elemento de proclamación de la filiación se junta el otro elemento de la tradición, el don del Espíritu según Is 11,2.

Un análisis más detallado descubre elementos del "siervo de Yahvé" a través de Is 42,1 y 49,1-19. El alcance de la escena es proclamar a Jesús como el mesias de los profetas ${ }^{20}$. La relación de los diversos elementos con la justicia es manifiesta.

A continuación del bautismo, viene la Tentación (cf. Mc 1,12). Los sinópticos ponen en estrecha relación el descendimiento del Espíritu sobre Jesús en el bautismo y la tentación. El tentador quiere apartar a Jesús del camino señalado por su Padre que es la predicación del "mispat" (la justicia) y que le llevará a la muerte. Jesús vence la tentación (por la fuerza del Espiritu) ${ }^{21}$. En el bautismo Jesús ha sido proclamado hijo de Dios y ha recibido el Espiritu de acuerdo con los rasgos capitales de la tradición mesiánica. Ahora

20. Indicaciones sobre estos puntos se encuentran en el estudio de $M$. A. CHEVALIIER, L'Esprit et le Messie: [cf. nota 15]. Y con más amplitud y profundidad en la monografia de F. LENTZEN-DEIS, "Die Taufe Jesu nach den Synoptikern". Frankfurt Main, 1970. Cf. también A. VARGAS-MACHUCA, "La narración del bautismo de Jesús y la exégesis reciente": Cultura Bíblica 30 (1973) 131-141.

21. La cuestión de la tentación de Jesús es un punto muy discutido y sujeto a revisión en cuanto al sentido primero $y$ al sentido que la redacción evangélica quiso darle. 
bien, es bajo el impulso de este espiritu mesiánico y en cuanto hijo de Dios como Jesús conocerá la prueba del desierto.

Notamos de paso una diferencia de vocabulario en Lucas que obedece sin duda a la evolución de la cristología. Hay en Lc 4,1 una variante respecto de $\mathrm{Mc}$ 1,12. En Lueas Jesús aparece volviendo del Jordán "lleno del Espíritu", y siendo conducido al desierto "en el espíritu". En Marcos es el Espíritu quien le lleva. La razón de la variante de Lucas es sin duda porque quiere evitar la subordinación de Jesús al Espíritu.

3. El Espíritu Santo y el Mesías en el relato de la concepción virginal.

Omitiendo muchas discusiones, parece estar claro un paralelismo con Juan Baustista para poner de relieve que siendo grande el Precursor; Jesús le supera. En lo referente al Espíritu, Juan aparece lleno del Espíritu desde el seno de su madre (Lc 1,15). Jesús aparece, y en mayor grado, en relación con el Espíritu, tanto que su origen está en el misterio del Espíritu Santo. El texto empalma por aquí con Is 11,2 .

El otro aspecto, el de la filiación proclamada, empalma con Sal 2,7 a través de Is $9,6-7$.

\section{Textos de Mateo referidos al Mesías en relación con el} Espiritu.

En Mt 12 y en Mt 18,17 se hace una aplicación a Jesús de pasajes del Deutero-Isaías referentes al Siervo de Yahvé ${ }^{22}$.

1. En Mt 12, 18-21 se cita a Is $42,1-4$.

El llevar el "mispat" (la justicia perfecta) a las naciones es la razón de ser o misión del Siervo. Es la justicia perfecta en favor de todos los desvalidos y menesterosos.

La misión del Siervo no es la basada en expiación que nos hemos formado sobre el cuarto canto (Is $52,13-53,12)^{23}$. Mateo ha interpretado los cuatro cantos como una obra conjunta e interpreta el cuarto a la luz del primero la misión del Siervo: es "krisis", justicia para todos los que sufren.

En Mt 8,17 no se trata de que Jesús tome sobre sí todas nues-

22. Cf. J. P. MIRANDA, Marx y la Biblia, 157-159.

23. Cf. E. FLESSMANN-VAN LEER, Die Interpretation der Passionsgeschichte von Alten Testament, en la obra colectiva "Zur Bedeutung des Todes Jesu 2" (1967) 89-90. 
tras dolencias, sino de que las suprima de sobre la faz de la tierra. Mateo lo ve cumplido en las curaciones. Pero esa obra de Cristo está atribuida en la cita a la circunstancia de que "Dios pone su espíritu sobre él" (Mt 12,18). Por eso añade "y anunciará la justicia a las naciones".

2. Es digna también de notarse la polémica que sigue a este pasaje y versa sobre si las obras de Cristo (de curaciones) son eficacia clel Espiritu de Dios o no.

Mt en 12,28 modifica la Quelle que decía: "en el dedo de Dios arrojo los demonios" (Lc 11,20). ¿Por qué la modificación? Mateo introduce al Espíritu en 12,18 y en 12,28 con lo cual consigue que la polémica de Marcos 3, 22-27 (asumida en Mt 12, 24-26) que no mencionaba al Espíritu de Dios para nada, desemboque con perfecta coherencia en el asunto del pecado contra el Espiritu Santo, (según Mt) en atribuir las obras de Cristo al "espíritu impuro" (Mc 3,30) y no al espiritu de Dios.

5. Utilización de Lucas de Is 61,1.

1. El comienzo del ministerio en Galilea que refieren $\mathrm{Mt}$ (4, 17) y Mc $(1,15)$, lo refiere Lucas $(4,16-30)$ de particular manera. Prescindimos de si Lucas utilizó una fuente peculiar o de si todo es trasposición redaccional. Cita a Is 61,1 (El Espiritu del Señor sobre mí...) dando asi el contenido de la predicación en la Sinagoga de Nazaret que no dan ni Mt ni Mc en este pasaje ${ }^{24}$.

Lucas hace del episodio la predicación inaugural de Jesús e incluye un resumen de su mensaje, lo mismo que ha hecho Marcos y Mateo en la presentación de la inauguración del ministerio público de Jesús. El resumen de la predicación que dan Mc y Mt es que "el reino de Dios ha llegado". El de Lucas es en la cita programática utilizada: "El Espíritu del Señor está sobre mí, puesto que me ha ungido, para anunciar una buena nueva a los pobres. Me ha enviado para proclamar a los cautivos la libertad y a los ciegos la recuperación de la vista, para enviar en libertad a los oprimidos, para publicar un año de gracia del Señor". Prescindimos de las pequeñas diferencias que existen con el texto original de Isaías.

Lucas ha sustituido la fórmula del Kerygma de Jesús que le ofrecía Marcos (el anuncio del reino y la invitación a conversión) porque para Lucas no era ese (o con tal modalidad) el verdadero resumen del mensaje mesiánico, sino el año de gracia.

24. Sobre la unción con el Espíritu, cf. I. DE LA POTTERIE, "L'onction du Christ": Nouvel Revue de Théologie 80 (1958) 225-252. 
Además, Lucas ha condensado en este texto como el "programa" de todo su libro, como es bien fácil ce observar. Este mismo procedimiento o método lo ha seguido en los Hechos de los Apóstoles. Tanto en el Erangelio como en los Hechos, Lucas coloca en labios de Jesús unas palabras que resultan programáticas (cf. Act 1,8). De esta manera, la misión de Jesús, ungido con el Espíritu Santo, es realizar un programa de "justicia", entendida "justicia" en el sentido amplio y comprensivo que hemos explicado en otra parte (y ese mismo jrograma será, según Act 1,8 , el de sus enviados).

2. ${ }^{\circ}$ Is 61,1 lo vuelve a utilizar Lucas en otros dos pasajes de los Hechos (Act 10,38 y 4,26) con una particularidad digna de atención:

a) En el discurso de Pedro, que es como un resumen del primitivo mensaje cristiano, es cle señalar la frase de Act 10,36: "La Palabra que él ha enviado a los hijos de Israel predicando el evangelio de paz por Jesucristo".

Dice Pedro: "Sabéis lo que ha sucedido... a continuación del bautismo cue Juan ha predicado, cómo Dios ha ungido a Jesús de Nazaret con el Espíritu Santo y con fuerza, y él iba haciendo el bien y sanando a todos los que estaban bajo el poder del diablo".

La frase "ungir con el Espiritu Santo". no puede provenir sino de Is 61,1: "El Espíritu Santo está sobre mí, porque él me ha ungido...". "Ungir con el Espíritu Santo" es algo desconocido en el Antiguo Testamento. En 1 Sam 10,1 y 6-7 y en 1 Sam 16,13 se describe al Espíritu de Yahvé que se apodera de Saúl y de David después de ser ungidos como reyes. La unción lleva consigo el don del Espíritu, pero no existe una unción del Espíritu. El alcance de Isaías 61,1, lo mismo que Isaías 11,2 no significa otra cosa sino que el Mesías será ungido como rey, en cuanto tal recibirá el Espíritu para cumplir su misión.

Jesús no ha recibido la unción de aceite de los reyes, pero en su bautismo ha recibido el Espíritu. Esa fue su unción y su proclamación regia que el discurso de Pedro utiliza para demostrar a Jesús como el Mesías que cumple los antiguos oráculos.

b) Otra alusión a la acción del Espíritu se encuentra en Act 4, 22 ss. En ese nasaje, Jesús queda equiparado al "ungido" del Salmo 2 en estos términos: "Tu santo siervo Jesús que tú has ungido" (4,27). Este pasaje tiene además de particular que une las dos designaciones cristológicas, "Siervo" y "Mesias", sin duda con una referencia implicita a Is 61,1 , donde originariamente ya el Siervo del DeuteroIsaías era considerado como Mesías.

3. De nuevo, la referencia a la justicia interhumana es ma- 
nifiesta sobre todo en 10,38. Lucas o el autor de los Hechos ve la entrega ilimitada del hombre a su prójimo como efecto distintivo del conferimiento del Espíritu: ("Cómo Dios lo ungió con Espíritu Santo y poder y él pasó haciendo el bien y sanando a los oprimidos por el Diablo, porque Dios estaba con él"). Tal fue la obra de Cristo y tal el contenido de su palabra, como se hace muy visible en San Juan, el amor al prójimo necesitado. La Biblia apunta aquí como en otros pasajes, hablando del Espíritu de Yahvé, como a una manera de ser y de actuar, como a una caracterización cualitativa, más que como a una hipóstasis o entidad o persona, aunque sea legitimo deducir la afirmación de estas categorias ontológicas.

\section{El Espiritu de Dios sobre Jesús, según Juan}

El cuarto Evangelio (aunque da en otros pasajes una cristología más evolucionada), conserva algunos rasgos de la "subordinación" del Mesias al Espíritu Santo en los relatos del ministerio de Jesús, según la tradición más antigua.

Juan Bautista declara que ha visto al Espiritu descender y permanecer sobre Jesús (Jn 1,32-34). Y en otro pasaje (Jn 3,34) se afirma: "El que Dios ha enviado dice las palabras de Dios, porque Dios no le da el Espiritu con medida" (cf. Is 11,2).

\section{El Espiritu de Dios en Jesús según Pablo (Rom 1, 3-4).}

Pablo nos conserva aqui un precioso testimonio sobre la asociación Espíritu-Mesías en la cristología más antigua. El hebraísmo "Pneuma agyosynes" subraya que sarx y pneuma se deben entender en el sentido judio. En el pasaje están subyacentes los temas corrientes de la tradición mesiánica.

Jesús como hombre (kata sarka) era un descendiente de David; podía pues ser legitimamente el Mesias. Ahora bien, de hecho ha sido establecido "hijo de Dios" en fuerza. Es el esquema que se encuentra en la escena del bautismo y en los relatos del Nacimiento en Lucas. En el primer caso, el davidida era proclamado "hijo de Dios" por una voz celeste; en el segundo caso, era reconocido hijo de Dios por el nacimiento virginal.

En Rom 1, 3-4 es establecido "hijo de Dios" en la resurrección (entronización) (como sucede también en Act 13,23 y 33 donde Sal 2,7 se ve cumplido en la resurrección).

Los dos puntos de la tradición dependiente de Salmo 2,7 e Is 11,2 se dan aquí en la fórmula paulina. El Espíritu Santo tiene su puesto para establecer al davidida Hijo de Dios. El Espiritu es indispensable para la proclamación del Hijo de Dios. El Espíritu San- 
to es enviado por Dios para calificar al Mesias. Es un poder de Dios que establece, consagra, unge e incluso engendra al davídida, hijo de Dios.

\section{El Espiritu Santo en la muerte de Jesús}

La asociación procede de un pasaje de Hebreos $(9,14)$ que se limita a afirmar que la muerte como ofrenda total al Padre fue realizada en virtud del "espíritu eterno".

9. Evolución, en la cristología, de subordinación al Espiritu a una asociación con el Espiritu.

\section{1. $\quad$ En Pablo}

Al Cristo proclamado "Señor" o "kyrios", al avanzar la cristología, no le convenía la fórmula de Is 61,1 "El Espíritu del Señor está sobre mí" (por lo que supone la subordinación). En adelante, la relación del Mesías y del Espíritu es una relación de asociación y no de dependencia. En la exaltación de Jesús se interrumpe, pues, la línea de tradición mesiánica del Salmo $2 \mathrm{y}$ del Isaías 11.

Hay otro factor que se añade a la "exaltación", y es la penetración del mensaje evangélico en el mundo griego y en su vocabulario y filosofía, como es la oposición metafísica del reino espiritual y del reino material. Pablo, (aun modificando la concepción) en la contraposición entre sarx y pneuma, expresa asi la oposición radical del reino de Dios y del reino del pecado ${ }^{25}$.

Emplea sarx, que no es la materia, sino la voluntad del hombre rebelado contra Dios; y el pneuma no es una esencia divino impersonal, es el poder, el amor, la acción del Dios de Jesucristo.

La fe en el Cristo glorificado asociado al "Espíritu del Señor", se convierte así en la fe en un reino "espiritual" de Cristo sobre la tierra como en el cielo, es decir, en una presencia activa y personal, aunque misteriosa del Resucitado. Jesús está asociado al reino del Espiritu.

\section{$2 .^{\circ}$ En el joannismo}

En el joannismo se desarrolla en una dirección análoga. La oposición del Espíritu y de la Carne - o del mundo- es más neta todavía que en Pablo, pero la esfera pneumática está allí también definida como el lugar donde Dios es personalmente soberano.

Hay una especie de identificación entre el Espíritu y Jesús. El

25. Para esta cuestión cf. nota 7 . 
Espíritu Santo viene como "sustituto" de Jesús (Jn 14,16 y 26; 15, $26 ; 16,7)^{26}$.

La cuestión de la relación entre el Mesias y el Espíritu queda enteramente renovada en su fondo por la glorificación de Cristo; -en su forma, y sin duda también en su fondo- por la penetración del Evangelio en ambiente helenístico.

En este aspecto, existe ya una interferencia entre la relación de Jesús con el Pneuma y la relación del creyente con el Pneuma.

\section{B. El Espíritu Santo actuando sobre los cristianos en orden a la justicia}

Hacemos una selección de pasajes, exponiendo primeramente el fenómeno de Pentecostés, pasando después en recuento una serie de textos bíblicos dispersos por los escritos de Juan y Pablo, para considerar finalmente, como en recapitulación, la constitución del bautismo cristiano y el hecho de la filiación adoptiva atribuida expresamente a la actuación del Espiritu.

\section{En Pentecostés}

El cumplimiento de lo prometido al nuevo pueblo de Israel se narra en la escena de Pentecostés ${ }^{27}$.

1. La relación entre el Espíritu y la justicia es manifiesta como lo era en la formulación de las promesas. San Lucas describe así el resultado del Espíritu en el nuevo pueblo cristiano: "La multitud de los creyentes tenía un solo corazón y una sola alma, y nadie llamaba propio nada de lo que tenía, sino que todas las cosas las tenían en común" (Act 4;32). Esta descripción es repetición substancial de Act 2, 44-45. Esta repetición delata la intención expresa de Lucas, y cuánto le importaba hacer constar cuál era el efecto de la veniala del Espiritu Santo. Por eso la pone a continuación inmediatamente de 4,31 , pues en Act 2 habia tenido que intercalar el discurso pentecostal de Pedro y no habia quedado suficientemente de relieve la conexión entre 2,4 y $2,44-45$.

26. Véase los penetrantes análisis que hace de los pasajes sobre el Espíritu R. E. BROWN en su magnífico Comentario a San Juan. En el segundo tomo tiene además un Excursus sobre el Pneuma. Más recientemente está la monografía de F. PORSCH, Pneuma und Wort. Ein exegetischer Beitrag zur Pneumatologie des Johannes-evangelium. Frankfurt Main, 1974.

27. Sobre Pentecostés en general puede verse el estudio que le dedica J. DUPONT, Études des Actes des Apôtres. Paris, 1967. 


\section{El Espiritu Santo y el don de lenguas ("glosolalia")}

El "don de lenguas" es un efecto visible del Espiritu Santo. Hay en la interpretación un simbolismo vinculado a este fenómeno pentecostal. Se discute sobre la identidad entre la glosolalia de Pentecostés y la glosolalia de la primera carta a los Corintios ${ }^{28}$.

En Pentecostés, las lenguas de fuego aparecen distribuyéndose, dispersándose (diameridsomienai) sobre los apóstoles.

La elección del término "diameridsomenai" pudiera no ser indiferente. Es la palabra que en el Cántico de Moisés expresa la dispersión de los pueblos (Dt 32,8): El Espíritu (uno) rehace en adelante la unidad de las lenguas diversificadas.

No se puede dudar que los dos temas, dispersión de pueblos y diversidad de lenguas, no estén ligados.

En esta línea, en la continuación del relato, el estilo de Lucas subraya constantemente detalles que ponen de relieve el alcance simbólico del milagro de las lenguas.

"Se pusieron a hablar en lenguas extrañas", según que el Espíritu les daba profetizar" (v. 4); había en Jerusalén "gentes de todo pueblo de los que están bajo el cielo" (v. 5); cada uno oía hablar en su propia lengua (vv. 6-8); se enumeran los pueblos diversos, que vienen de todos los extremos del horizonte.

No hay que olvidar que Jesús mandó a los Apóstoles "ser sus testigos hasta la extremidad de la tierra" (Act 1,8), para comprender que su misión de enseñar a las naciones comienza al menos simbólicamente en Pentecostés. El don de lenguas, como orden divina en acción, según los PP., revela a los Apóstoles su misión de enseñar a todas las naciones y de traerlas a la unidad.

Trasfondo de Pentecostés es también el relato de la Torre de Babel y la confusión de lenguas. Babel y su confusión idiomática fueron un castigo de Dios. La única frontera de los hombres es la del idioma. La lengua que divide, separa y desune a los hombre para enfrentarlos y llenarlos de odio. Contra las lenguas que dividen, el milagro de inteligibilidad que une en el amor.

\section{Textos dispersos de Juan y Pablo}

\section{Juan}

El Espiritu de Dios en los cristianos aparece también en San

28. Cf. L. CERFAUX, "Le symbolisme attaché au miracle des langues": Ephemerides Theologicae Lovanienses 13 (1936) 256-259. 
Juan, en esta misma línea de pensamiento, como caracterización cualitativa. El amor del prójimo en San Juan es el amor al prójimo que tiene necesidad (cf. $1 \mathrm{Jn}$ 3,17). Véase $1 \mathrm{Jn}$ 4, 12-13: "En esto conocemos que permanecemos en él y él en nosotros, en que nos ha dado de su espiritu". Cómo no va a ser el amor del prójimo (meta de la intervención de Dios) la señal de que Dios está en nosotros, cuando amamos al prójimo. En esto conocemos que Dios está en nosotros y nosotros en él, en que tenemos su mismo espíritu".

\section{2. ${ }^{\circ}$ San Pablo}

Pablo entiende también el Espíritu de Dios como caracterización cualitativa de espiritu de justicia. Veamos algunos textos:

a) Lo demuestra precisamente Gal 3,14 (citado antes), donde Pablo traduce por "promesa del Espiritu" la promesa de justicia que se le hizo a Abraham. Está explícito en Gal 5,22: "El fruto del Espíritu es el amor".

En Gal 5, 13-25 aparece claramente que "caminar en el espiritu" (v. 25) es equivalente a "por medio del amor servíos unos a otros". Merece reproducirse todo el pasaje: "Servios por amor los unos a los otros. Pues toda la ley alcanza su plenitud en este solo precepto: Amarás a tu prójimo como a ti mismo. Pero si os mordéis y os devoráis mutuamente, mirad no vayáis mutuamente a destruiros. Por mi parte os digo: Si vivís según el Espiritu, no daréis satisfacción a las apetencias de la carne. Pues la carne tiene apetencias contrarias al espiritu, y el espiritu contrarias a la carne, como que son entre sí antagónicos, de forma que no hacéis lo que quisiérais. Pero, si sois conducidos por el Espíritu, no estáis bajo la ley. Ahora bien, las obras de la carne son conocidas: fornicación, impureza, libertinaje, idolatría, hechiceria, odios, discordia, celos, iras (la vulgata añade "homicidios". (cf. Rom 1,29), rencillas, divisiones, disensiones, envidias, embriagueces, orgias y cosas semejantes, sobre las cuales os prevengo, como ya os previne, que quienes hacen tales cośs no heredarán el reino de Dios.

En cambio el fruto del espiritu es amor, alegría, paz, paciencia, afabilidad, bondad, fidelidad, mansedumbre, templanza (adición: castidad); contra tales cosas no hay ley. Pues los que son de Cristo Jesús, han crucificado la carne con sus pasiones y sus apetencias.

Si vivimos según el Espíritu, obremos también según el Espíritu. No busquemos la gloria vana provocándonos los unos a los otros envidiándonos mutuamente". 
b) Es tal vez el pasaje de Rom 5, 1-5 donde la relación entre Espíritu y Justicia (Amor) está más claramente expresada ${ }^{29}$.

En Gal 3, 6-14 Pablo habia afirmado que la promesa de justicia a Abraham se cumplía mediante el conferimiento del Espíritu Santo. En Rom 4, hablando de la misma promesa a Abraham, nàda se habia dicho del cumplimiento por medio del conferimiento del Espíritu. Pero eso se dice en Rom 5,5 que forma una unidad con Rom 4. Se dice en Rom 5,5: "Y la esperanza no defrauda porque el amor de Dios ha sido vertido en nuestros corazones por medio del Espiritu Santo que se nos ha dado".

Aqui hay que ver el sentido preciso de "amor" en la frase "amor de Dios", y si “de Dios" es genitivo objetivo o subjetivo. La controversia es clásica y desde los Santos Padres hay autores para una y otra posición. Parece que está claro que se trata de amor al prójimo.

En el lugar paralelo (ideológicamente) en Gal 5,22 se afirma "el fruto del Espíritu es el amor", y no hay duda, por el contexto, que se trata de amor del prójimo. El versículo tiene intención definitoria, de suerte que un amor que haya sido vertido en los corazones (Rom 5,5) por medio del Espíritu Santo no puede ser sino el amor al prójimo.

En cuanto al genitivo (amor de Dios) se ve por 5,8 que retoma el asunto diciendo "Dios demuestra el amor que nos tiene...", que se trata de "genitivo subjetivo".

Retraía de este modo de entender el que el amor de que Dios es sujeto se derrame en nuestros corazones. Pero no es ninguna dificultad desde el momento que se capta el sentido del Espíritu de Dios en la Biblia como "caracterización distintiva" antes que cualquier otra cosa ontologizante.

Asi pues, según Rom 5,5, es ese amor con que Dios ama a los hombres el que ha sido derramado en nuestros corazones, y precisamente por eso tenemos ya una esperanza que no puede fallar. Porque el fundamento de la esperanza consiste en que la "justicia de Dios" ya está en la tierra y es la que va a transformar el mundo y todas sus estructuras civilizatorias.

3. El bautismo cristiano y el espiritu

Hay un único espíritu en Cristo y en los cristianos, según 1 Cor

29. Cf. J. P. MIRANDA, Marx y la Biblia, 260. 
12, 1-13, y esta comunicación tiene lugar en el bautismo. El bautismo cristiano está conflgurado sobre el bautismo de Jesús ${ }^{30}$.

1. Según las fuentes, en el bautismo cristiano el creyente no sólo recibe el Espíritu Santo, sino que queda constituido al mismo tiempo como hijo de Dios.

Consta claramente del diálogo de Jesús con Nicođemus ( $\mathrm{Jn} 3$, 3-5). Se trata ahi de un nuevo nacimiento por el que se pasa a ser "hijo de Dios" (cf. Jn 1,12;14,16-18). Ahora bien, ese nuevo nacimiento se le designa como "nacimiento del agua y del Espíritu". Queda establecida una estrecha relación entre "agua, espiritu y nuevo nacimiento".

\section{2. ${ }^{\circ}$ Lo mismo consta por pasajes de Pablo.}

En Rom 6-8 se habla de una vida nueva que comienza con el bautismo. El tema de Pablo es que el bautizado, muerto y resucitado con Cristo, entra en una vida nueva que se caracteriza en el cap. 8 como vida según el Espíritu en calidad de "hijo de Dios" (Rom 8, 14-17).

En 1 Cor 6,11 y 12,13 se dice expresamente que el bautismo procura el Espiritu: "Habéis sido lavados, habéis sido santificados, habéis sido justificados en el nombre del Señor Jesucristo y en el Espíritu de nuestro Dios". "Porque en un solo Espíritu hemos sido todos bautizados, para no formar más que un cuerpo, judíos y griegos, esclavos y libres. $Y$ todos hemos bebido de un solo Espiritu".

Igualmente de Gal 3,26 a 4,7 Pablo enlaza los tres términos: bautismo, don del Espíritu y adopción filial. "La prueba de que sois hijos es que Dios ha enviado a nuestros corazones el Espiritu de su Hijo que clama: Abba, Padre".

Lo mismo se puede decir de Ef 1,5-13 que expone el plan de Dios. "Eligiéndonos de antemano para ser sus hijos adoptivos por medio de Jesucristo. En él también vosotros, tras haber oído la palabra de la verdad, el Evangelio de vuestra salvación y creído también en él, fuistéis sellados con el Espíritu Santo de la Promesa".

Igualmente en otro pasaje del deuteropaulinismo, Tit 3, 4-7: "Mas cuando se manifestó la bondad de Dios nuestro Salvador y su amor a los hombres (cf. Prólogo joánnico), él nos salvó no por obras de justicia que hubiésemos hecho nosotros, sino según su misericordia por medio del baño de regeneración y de renovación del Espíritu Santo, que derramó sobre nosotros con larguezá por medio de

30. Cf. M. A. CHEVALLIER, L'Esprit et le Messie, 108-109. 
Jesucristo nuestro salvador, para que justificados por su gracia, fuésemos constituidos herederos, en esperanza, de vida eterna". Aparecen los dos efectos del bautismo, nuevo nacimiento, comunicación del Espíritu Santo.

3." La constante asociación en las Epistolas entre el bautismo por una parte y la posesión del Espíritu y el estado de filiación por otra, remite al pautismo de Jesús como parte de la tradición primitiva tanto acerca de Jesús como acerca del significado del bautismo.

Estas caracterizaciones del bautismo cristiano que incluyen el don del Espiritu y la adopción filial están íntimamente relacionadas con el bautismo de Jesús.

El bautismo de Jesús, a la orilla del Jordán, es una descripción de la Iglesia primitiva donde hace una aplicación de su teologia sobre Jesús de Nazaret. Dos rasgos eran característicos de la figura del Mesías tradicional. El estar constituido "hijo" por un decreto celeste, según el Salmo 2, y el ser beneficiario del Espíritu, según Is 11. Estos dos rasgos de la tradición constan claramente por la literatura intertestamental. Là Iglesia primitiva se los aplicó a Jesús para afirmar de él que era el enviado de Dios, y después, a imagen del bautísmo de Jesús, configura el bautismo cristiano.

\section{4. $\quad$ Es importante también hacer otra observación}

El bautismo de Jesús ha sido retocado en favor de la teologia del Siervo. De la misma manera la interpretación del bautismo cristiano ha sido reelaborada para introducir la soteriologia de la cruz (cf. Mc 10,38: ¿Podéis ser bautizados con el bautișmo con que yo voy a ser bautizado?).

\section{La filiación adoptiva en expresa relación con el Espíritu $y$ con la justicia.}

Los textos para este punto están en Pablo. Pero empezamos tomando compendiosamente una presentación determinada, en la teologia joánnica, de la filiación divina. En algunos pasajes de la teología joánnica, se pone el acento, tanto en lo referente a la filiación divina de Jesús como en la fliación divina de los cristianos, más bien que en lo ontológico, en el proceder moral de justicia que es el mismo que caracteriza al Padre.

1. $\quad$ Para el punto primero, podemos fijarnos en la enconada controversia del capítulo 5 del cuarto evangelio. De esa controver- 
sia surge neto el sentido o el acento que se le da a la filiación civina de Cristo ${ }^{31}$.

La controversia que se narra en 5, 16-30 (con el complemento de 7, 19-24 que refiere la conclusión de este episodio) versa sobre la "obra buena" descrita en 5, 1-15 (una curación en sábado). Jesús cura en sábado, porque el hacer el bien está por encima de todo, cosa cue hace rebelarse a los judíos.

En 5, 19-20 hay una comparación. Dios es comparado a un obrero que trabaja, y su hijo, al hacer curaciones, trabaja él también a su. manera, aun en sábado, haciendo las mismas "obras" que el Padre, como del mismo oficio. Hay aquí una parábola oculta. (Un hijo aprende y practica el mismo oficio de su padre artesano) ${ }^{32}$. En la formulación "no puede un hijo hacer por su cuenta nada sino lo que viere hacer al padre" (Jn 5,19), el artículo antes de "hijo" y antes ce "padre" es artículo genérico como en Mc 3,27. No designa ni a Dios Padre ni a Dios Hijo. La parábola dice que un artesano (como sucedía ordinariamente en la antigüedad) le enseña a su hijo la técnica de su oficio. Lo que se desprende de la parábola es: Como el trabajo de un artesano es igual al de su padre, la identidad de actividad, el inconfundible tipo de "obras", el de las "obras buenas" que practica Jesús, está delatando que Dios es su Padre. La filiación es entendida como identidad de actividad, como igualdad de obras buenas. Lo que caracteriza a Dios es la bondad, la justicia. Jesús está también caracterizado por eso mismo.

No se trata de negar o poner en duda la divinidad ontológica de Jesucristo o la filiación natural, sino de entender algo que para Juan es mucho más importante que la divinidad de Jesucristo. La insistencia de Juan está en la identidad de tas "obras" (que no son los "milagros"), y mucho debe cifrar el Evangelista en esa identidad puesto que torna sobre ella en muchas ocasiones (cf. 9, 1-5, etc.).

Es especialmente significativo Jn 10, 37-38: "Si no hago las obras de mi Padre, no me creáis. Mas, si las hago, aunque no me creáis a mi, creed a las obras". Las "obras del Padre", tal como se había revelado en el A.T., "obras de amor, obras de justicia con los necesitados", identifican como venido de Dios y actuando en nombre de Dios a uno que hace esas mismas obras. Esto es lo que le interesaba a Juan afirmar como mensaje, más que otros aspectos posibles de revelación. La inconfundible cualidad de esas obras que revelan a Dios es lo único decisivo.

31. Cf. J. P. MIRANDA, El ser y el Mesias (Salamanca 1973) 136-138.

32. Cf. C. H. DODD, Une parabole cachée dans le quatrième évangile. 
2: Se da coincidencia de pensamiento cuando las Cartas de Juan se refieren a la filiación divina de los cristianos. El tema procede del Evangelio ( $\mathrm{Jn}$ 1,13) donde se dice que sólo son capaces de recibir la "Palabra" los que han nacido de Dios. A esto se debe la diferencia de actitudes. La proposición inversa ("Sólo son hijos de Dios (o nacidos de Dios) los que reciben la "Palabra") está explícita en las Cartas.

Son permutables entre sí las expresiones "nacer de Dios", "ser de Dios", "ser hijos de Dios" (cf. 1 Jn 3, 9-10 y Jn 2,29; 3,1 y en la pericopa 1 Jn 5, 1-2). Ahora bien, lo que significan estas expresiones, según las Cartas, es que los "hijos de Dios" están constituidos para "hacer justicia".

"Todo el que hace justicia es nacido de Dios" ( 1 Jn 2,29).

"Todo el que ama (se entiende, al prójimo) es nacido de Dios $1 \mathrm{Jn} 4,7$.

"En esto se conocen los hijos de Dios y los hijos del diablo: Todo el que no hace justicia no es de Dios, ni tampoco el que no ama a su hermano" (1 Jn 3,10).

"Querido, no imites lo malo sino lo bueno: el bienhechor es de (ek) Dios" (3 Jn 11).

Juan no hace diferencia entre amar al prójimo y hacer justicia. El "amor" de Juan es amor a los menesterosos, a los pobres, a los necesitados (cf. $1 \mathrm{Jn} 3,17-18$ ): "Si alguno que posee bienes de la tierra (sobre todo, superfluos), ve a su hermano padecer necesidad y le cierra su corazón, ¿cómo puede permanecer en él el amor de Dios? (de Dios) (genitivo subjetivo). Hijos mios, no amemos de palabra, ni de lengua, sino con obra y de verdad".

3..$^{\circ}$ El tema de la filiación divina por las obras de justicia se encuentra también fuera de Juan, en los Sinópticos.

Lc 6, 35-36: "Amad a vuestros enemigos; haced el bien y prestad sin esperar nada a cambio, y vuestra recompensa será grande, y seréis hijos del Altísimo, (porque él es bueno con los ingratos y los perversos). Sed compasivos, como vuestro Padre es compasivo".

Mt 5, 44-45 y Mt 5,9: "Bienaventurados los realizadores de la paz (mesiánica, basada en la justicia, Is 32,15), pues son ellos los que serán llamados hijos de Dios".

Mt 5, 16: "Vean (los hombres) vuestras "obras buenas" y glorifiquen a vuestro Padre celeste" (En las "obras buenas" comprobarán que sois hijos de Dios y que Dios actúa en vosotros"). 


\section{Hijos por el Espiritu Santo en textos paulinos}

La misma concepción de la filiación divina se encuentra en algunos textos paulinos con la particularidad de vincularla al Espíritu Santo. Es el Espiritu Santo quien efectúa nuestra filiación divina (Rom 8,9 ss.; Gal 4,6) ${ }^{33}$.

Según las palabras de Pablo, resulta expresamente que Dios nos concede el Espíritu Santo para llegar a ser hijos adoptivos. Es por el Hijo (Gál 4,5), en el Espíritu Santo $(4,6)$, como el Padre nos adopta. Lo mismo que envió el Hijo para hacer posible nuestra adopción, envía también al Espiritu para realizarla.

San Pablo emplea diferentes imágenes para señalar ese don del Espíritu: "Todos nosotros hemos sido abrevados de un solo espíritu (1 Cor 12,13)". "Es Dios quien nos ha marcado con su sello $y$ ha puesto en nuestros corazones las arras del espíritu" (2 Cor 1,22; cf. Ef 1,13 ss.; 4,30 ).

En Rom 8,15 aparece "el Espíritu de la adopción". El pasaje de la carta a los Romanos que evoca la oración "Abba" (8, 9-15) explica igualmente que es precisamente el Espíritu Santo quien. confiere la adopción. El v.14 indica claramente que el estado de filiación es debido a la presencia del Espíritu y a su acción vivificante "En efecto, todos a los que anima el Espíritu de Dios, son Hijos de Dios": Ese aspecto moral está indicado más claramente en Rom 8,9: "Vosotros no estáis en la carne, sino en el Espíritu, puesto que el Espíritu habita en vosotros". Anteriormente, en Rom 8,5, se había contrapuesto la conducta de la carne y la conducta del espíritu: "Porque los que son según la carne, aspiran a las cosas de la carne, mas los que son según el espíritu, a las del espiritu". Hecho el estudio teológico pertinente a través del "Corpus paulinum", aparece que carne es la contraposición a espíritu y que "caminar en el espíritu" aparece caracterizado por caminar en la justicia. Esto se hace patente por Gal 5, 13-25, donde "caminar en espíritu" (v. 25) significa precisamente "por medio del amor servios unos a otros". "Espíritu de Dios" se toma como caracterización cualitativa de Dios que interpela a la justicia interhumana. "Carnalidad" es donde acaban los caminos de Dios. Todo proceder injusto es "proceder según la carne". "Carne" significa para Pablo la existencia del hombre en cuanto perteneciente al viejo eón, al viejo mundo.

33. Para esta sección cf. S. ZEDDA, en su obra citada en la nota 8; cf. también W. MARCHEL, Abba Père: La priere du Christ et de chrétiens: III: La prière "Abba" et l'action du Saint Esprit (Roma 1963) 232-243. 
Y prosigue el Apóstol en el pasaje de Romanos declarando que la pertenencia a Cristo depende de la presencia del Espíritu ( ( .9): "Quien no tiene el espíritu de Cristo, no le pertenece (aspecto moral); lo mismo, su presencia es necesaria para hacer morir "las obras del cuerpo" (v. 13).

Por lo tanto "recibir el Espiritu de Dios" es para el hombre hacerse verdaderamente hijo de Dios; dicho de otra manera, comunicándose al creyente y residiendo en él, el Espíritu le hace hijo adoptivo de Dios. Siendo así que la presencia activa del Espíritu en el cristiano le hace hijo, se puede decir que el Espíritu Santo es la causa inmediata de la adopción.

\section{Los minitros de la Palabra y los discípulos equipados con el Espiritu}

Una de las ideas clave del cuarto evangelio en el Sermon de la Ultima Cena es la afirmación de la vuelta de Jesús en el Espiritu para que siga su presencia dinámica en los que van a ser servidores de la Palabra, de la Palabra efectuadora de Justicia. Es otra forma de expresar la idea de la llamada "escatología realizada" difusa por todo el cuarto evangelio. Vamos a tratar de medir el alcance de esta afirmación ${ }^{34}$.

Podriamos decir en una frase compendiante que el Paráclito es el Espiritu entendido como la presencia dinámica ya desde ahora del ausente Jesús en los discípulos para ser los realizadores de las "grandes obras" del amor al prójimo, sintesis de la predicación de dasús. Lo mismo de la presencia de Jesús en los discípulos que la presencia del Espiritu (cf. Jn 14, 15-17 y Jn 14, 18-21). No se trata de dos presencias sino de una misma e idéntica presencia. Desde esta afirmación podemos entender las afirmaciones de una serie de textos.

1. En Jn 20,29 se proclaman felices a los que sin ver creyeron. La razón está en la presencia del Espíritu, diríamos, de más densidad que lo fuera la presencia física de Jesús. El Espíritu no es un sucedáneo del Cristo que se ha ido. Pone a los discípulos (a los inmediatos y a los subsiguientes) en un contacto mucho más radical con el Maestro que el que habian tenido durante la vida pública cuando vivian cotidianamente a su lado.

34. Como bibliografia para este punto remitimos al Comentario sobre San Juan de R. E. Brown, y a indicaciones dispersas a través de "El ser y el Mesías" de J. P. Miranda [cf. nota 31 ]. 
Esta mejor condición da la explicación del texto (Jn 16,7) en que Jesús dice a los discípulos: "Os conviene que yo me vaya, porque si no me voy no viene a vosotros el Paráclito, pero si me voy os lo enviaré". Por qué conviene más la presencia de Jesús llamada Espíritu que la presencia corporal misma se explica en Jn 16,8 y en 15, 26-27 por el testimonio que el Espíritu dará a través de las obras buenas, que según Jn 14,12 serán mayores que las de Jesús mismo. Las "obras" reveladoras de Dios (Jesús lo que quiere es revelar a Dios) serán más abundantes en los discípulos que lo fueron en él, $\mathrm{Y}$ esto es lo importante. La verdadera presencia es la realización plena del estatuto o contenido de la palabra.

2. El tiempo de la venida de Jesús es Pentecostés, que en $\mathrm{Jn}$ coincide con el día de la resurrección (cf. 20,19,23) cumpliéndose 10 que se habia dicho que no había Espíritu porque Jesús no habia sido glorificado $(7,39)$.

Algunos textos del Discurso parecen militar contra la inmediata vuelta de Jesús, y la interpretación se desorienta a veces bajo mentalidad ultramundana. Jn 14,1 comienza con "voy a prepararos un lugar", "en casa de mi Padre hay muchas mansiones", "volveré y os tomaré conmigo", frases que parecen hablar de una realidad futura. Pero no se trata de "moradas celestes" (v. 2) o de grados de felicidad celeste sino de que en el servicio de Dios hay muchos puestos.

En 14,23 se explica el sentido verdadero de "morada" que tiene lugar en los creyentes mismos que viven en el mundo: el Padre y Jesús vendrán al creyente y "harán morada en él". Ahí está la morada definitiva. En 14,16 se envia el Espíritu "para que se quede con ellos para siempre" (eis ton ayóna). En 14,12 se dice que el creyente hará "obras mayores" que Jesús (lo cual no puede ser en el otro mundo). Precisamente en esas obras que interpelan al mundo consistirá la presencia del Paráclito, en la cual se sintetiza la presencia del Padre y el retorno de Jesús. Se trata de cambiar el mundo, éste, no otro para lo que se necesitan las obras mayores.

Por 14, 13-14 se ve de nuevo que la "morada" del v. 3 se refiere a este mundo, puesto que no tendria sentido, si supone a los discipulos en el cielo, el decirles que "todo lo que pidieren al Padre en su nombre, Cristo lo hará". En esta oración de los discipulos mencionada en varios pasajes $(14,13-14 ; 15,7-16 ; 16,23-24.26)$, se trata de cambiar este mundo a base de "la palabra" y de "las obras buenas". Esa es la "morada" y es la "parusía" y es la "venida del Reino", que también se pide en el "Padrenuestro". Lo que en realidad se pide es la transformación del mundo. 
La "paz" de 14,27 es la paz mundial escatológica. La frase del 14,20 "en aquel día" es frase técnica para indicar el cumplimiento escatológico. $Y$ sería; según ese versículo, la inhabitación de Jesús en los discipulos después de la resurrección, por medio del Paráclito.

Tämbién el 14,18 ("No os dejaré huérfanos") tiene lugar mediante la presencia del Paráclito.

$Y$ finalmente lo que Jesús dice en la "oración sacerdotal" (17, 24): "quiero que donde yo estoy (en presente) estén ellos, en este momento del transferimiento de la Palabra a otros portadores, en este relevo, el sentido parece claro; Jesús está todavía en función trascendente de Palabra dirigida al mundo. Ahí es donde quiere que en adelante estén los discípulos bajo la acción del Espíritu, su presencia dinámica.

José Alonso Díaz, SJ. Universidad de Comillas Madrid 